\title{
Managing treatment-related peripheral neuropathy in patients with multiple myeloma
}

This article was published in the following Dove Press journal:

Blood and Lymphatic Cancer:Targets and Therapy

29 June 2016

Number of times this article has been viewed

\section{Sara Grammatico \\ Laura Cesini \\ Maria Teresa Petrucci \\ Division of Hematology, Department of Cellular Biotechnologies and Hematology, Sapienza University, Rome, Italy}

\begin{abstract}
Peripheral neuropathy is one of the most important complications of multiple myeloma treatment. Neurological damage can be observed at the onset of the disease, due to the effect of monoclonal protein or radicular compression, but more often is treatment related. Vinca alkaloids in the past era, and more recently, thalidomide and bortezomib are mainly responsible. Degeneration of dorsal root ganglion is common, prevalently related to angiogenesis inhibition and cytokine modulation in the case of thalidomide and inhibition of the ubiquitin proteasome system in the case of bortezomib. Sensory neuropathy and neuropathic pain are more common; motor neuropathy and autonomic damage are less frequently observed. Neurotoxicity often affects patient's quality of life and requires dose modification or withdrawal of therapy, with a possible effect on the overall response. A prompt recognition of predisposing factors (such as diabetes mellitus, alcohol abuse, vitamin deficiencies, or viral infections) and appearance of signs and symptoms, through a periodic neurological assessment with appropriate scales, is extremely important. Effective management of treatment at the emergence of peripheral neuropathy can minimize the incidence and severity of this complication and preserve therapeutic efficacy. Dose adjustment could be necessary during treatment; moreover, gabapentin or pregabalin, tricyclic antidepressants, serotonin and norepinephrine reuptake inhibitors, carbamazepine, and opioid-type analgesics are suggested according to the pain severity. Some authors reported that patients who develop peripheral neuropathy during their multiple myeloma treatments presented a particular gene expression profile; therefore, future studies could be helpful for a better understanding of possible biological pathways underlying neurotoxicity.

Keywords: neurotoxicity, thalidomide-induced peripheral neuropathy, bortezomib-induced peripheral neuropathy
\end{abstract}

\section{Introduction}

Over the past decade, new treatment options, such as the proteasome inhibitor (PI) bortezomib and the immunomodulatory drugs (IMiDs) thalidomide and lenalidomide, have dramatically changed the outcome of multiple myeloma (MM) patients, improving response and long-term survival. These new drugs are now the milestones of MM treatment regimens, for either newly diagnosed or relapsed/refractory patients. However, these compounds are not free from side effects. Treatment-related peripheral neuropathy (PN), defined as damage, inflammation, or degeneration of the peripheral nerves, is an important complication observed in MM patients, which often leads to reduction or withdrawal of therapy, with an impact on efficacy and response to treatment and a significant effect on patient's quality of life.
Correspondence: Maria Teresa Petrucci Division of Hematology, Department of Cellular Biotechnologies and Hematology, Sapienza University, via Benevento 6, 00161 Rome, Italy

Tel +390649974430

Fax +3906441639810

Email petrucci@bce.uniromal.it 
This review focuses on the clinical signs and symptoms, diagnosis, and risk factors of $\mathrm{PN}$, particularly dealing with the incidence, mechanisms, and management of thalidomideinduced peripheral neuropathy (TiPN) and bortezomibinduced peripheral neuropathy (BiPN).

\section{Signs and symptoms}

Patients prevalently describe numbness/tingling in hands and feet, burning pain, altered sensitivity to touch and heat, muscle weakness, skin or nail changes, and/or lack of coordination. In fact, sensory neuropathy and neuropathic pain are more common; therefore, hyperesthesia, hypoesthesia, and paresthesia are very often referred, usually in a distal stocking-and-glove distribution over the hands and feet, frequently associated with altered heat and cold sensation. Additionally, sensory PN can lead to areflexia and loss of proprioception. Symptoms or signs of motor and/or autonomic nervous system damage can also emerge, even if less frequently. Motor symptoms prevalently occur in the case of a severe sensory PN causing muscle cramps, muscle atrophy, or loss of strength in distal muscles. Rarely, orthostatic hypotension, bradycardia, constipation, or impotence can occur as signs of autonomic damage. ${ }^{1-6}$

\section{Diagnosis and evaluation}

Accurate evaluation of signs and symptoms is extremely important. The most widely accepted scale for a quantitative evaluation of $\mathrm{PN}$ is the National Cancer Institute - Common Toxicity Criteria score, Version 4.0 (Table 1). ${ }^{7}$ An alternative is the neurotoxicity subscale defined by the neuropathy-specific Functional Assessment of Cancer Therapy/Gynecologic Oncology Group, which is a questionnaire for patients undergoing systemic chemotherapy. ${ }^{8,9}$ The first assesses the extent of sensory and motor peripheral nerve damage caused by chemotherapy, while the neurotoxicity subscale evaluates sensory, motor, and hearing neuropathies and dysfunctions associated with neurotoxicity. Unfortunately, the degree of PN is very subjective and dependent on patients' reporting, so a uniform and reliable interpretation of data is not so easy. Another evaluation method is the total neuropathy score (TNS), which is a complete assessment of symptoms, signs, ability aspects, and electrophysiology. The TNS can be reduced or purely clinical (Table 2). The TNS in the complete version includes the quantitative determination of the vibration perception threshold. The reduced TNS includes the electrophysiological examination of one sensory (sural) nerve and one motor (common peroneal) nerve. The purely clinical version is based on the evaluation of sensory, motor, and autonomic symptoms, pin and vibration sensibility, muscle strength, and deep tendon reflexes. However, electrophysiologic examination is not always available and applicable. ${ }^{10}$ Recently, also the Treatment-Induced Neuropathy Assessment Scale has been evaluated. ${ }^{11}$ Regardless of the method or scale used, a regular and focused neurological examination (touch, pain, temperature, vibration, proprioception), distal muscle strength, ankle reflexes, and supine versus upright blood pressure evaluations are recommended. Nerve conduction studies (NCS) and needle electromyography may confirm the diagnosis of PN, identifying the neural structures involved, the presence of axonal degeneration or demyelination, and the severity of axonal damage. Particularly, thalidomide often causes axonal sensorimotor PN with reductions in sensory nerve action potentials (SNAPs) and distal compound motor nerve action potentials with denervation and reinnervation in distal muscles on needle electromyography. Bortezomib produces axonopathy less frequently and leads to a decrease in nerve conduction velocity only if demyelination is present. However, a discrepancy between neurophysiological assessment and clinical presentation is common because the damage to small fibers, which are prevalently involved, does not produce clear changes in the classic nerve conduction. Moreover, even if alterations in SNAPs are detected, recovery of SNAPs does not seem to correlate necessarily with clinical improvement. Recently, quantitative sensory testing has been introduced for evaluating sensation of small fibers. This method evaluates thermal (warm, cold) and pain (cold pain, heat pain) thresholds in the selected dermatomes. This test appears simple and fast, but it needs good cooperation between an examiner and a patient. ${ }^{12}$ Also, the evaluation of the quality of life in case of a chemotherapy-induced PN is fundamental. The European Organisation for Research and Treatment of Cancer developed a questionnaire for selfevaluation by patients (QLQ-CIPN20) that is currently used in international studies. ${ }^{13,14}$

\section{Risk factors}

Sometimes PN is caused by the disease itself and can be observed at the diagnosis, before starting treatment, in approximately one-quarter of patients. Therefore, symptoms are amplified by the therapy. Neurological symptoms related to plasma cell dyscrasias can be observed in not only MM but also amyloidosis, cryoglobulinemia, immunoglobulin $\mathrm{M}$ deposition, or POEMS syndrome. The possible etiologies are multiple: direct compression of nerves by plasmacytomas or bone lesions, amyloid deposition, immunoglobulin $\mathrm{M}$ antibodies against the myelin-associated glycoprotein, 
Table I Peripheral neuropathy according to $\mathrm{NCl}-\mathrm{CTC}$ Version 4.0

\begin{tabular}{|c|c|c|c|c|c|}
\hline \multirow[t]{2}{*}{ Adverse event } & \multicolumn{5}{|l|}{ Grade } \\
\hline & $\mathbf{I}$ & 2 & 3 & 4 & 5 \\
\hline $\begin{array}{l}\text { Peripheral motor } \\
\text { neuropathy }\end{array}$ & $\begin{array}{l}\text { Asymptomatic, clinical or } \\
\text { diagnostic observations only, } \\
\text { intervention not indicated }\end{array}$ & $\begin{array}{l}\text { Moderate symptoms, } \\
\text { limiting instrumental } \\
\text { ADL }\end{array}$ & $\begin{array}{l}\text { Severe symptoms, } \\
\text { limiting self-care ADL, } \\
\text { assistive device indicated }\end{array}$ & $\begin{array}{l}\text { Life-threatening } \\
\text { consequences, urgent } \\
\text { intervention indicated }\end{array}$ & Death \\
\hline $\begin{array}{l}\text { Peripheral sensory } \\
\text { neuropathy }\end{array}$ & $\begin{array}{l}\text { Asymptomatic, loss of } \\
\text { deep tendon reflexes or } \\
\text { paresthesia }\end{array}$ & $\begin{array}{l}\text { Moderate symptoms, } \\
\text { limiting instrumental } \\
\text { ADL }\end{array}$ & $\begin{array}{l}\text { Severe symptoms, } \\
\text { limiting self-care ADL }\end{array}$ & $\begin{array}{l}\text { Life-threatening } \\
\text { consequences, urgent } \\
\text { intervention indicated }\end{array}$ & Death \\
\hline Neuralgia & Mild pain & $\begin{array}{l}\text { Moderate pain, limiting } \\
\text { instrumental } A D L\end{array}$ & $\begin{array}{l}\text { Severe pain, limiting self- } \\
\text { care ADL }\end{array}$ & - & - \\
\hline
\end{tabular}

Note: Data from National Cancer Institute. ${ }^{7}$

Abbreviations: $\mathrm{NCI}-\mathrm{CTC}$, National Cancer Institute - Common Toxicity Criteria; ADL, activities of daily living.

or cytokine-mediated injury against a glycoconjugate component of nerves involved in the interactions between Schwann cells and axons. These factors can produce a smallfiber injury, segmental demyelination, or axonal degeneration. $\mathrm{MM}$-associated $\mathrm{PN}$ is primarily sensory or sensorimotor, and symptoms are predominantly symmetric, including paresthesia, numbness, burning sensation, and weakness, often with mild intensity, rarely inactivating or life threatening. ${ }^{46,15-19}$ Even if rare, it is important to investigate a neuronal damage that is typically demyelinating, peripheral, ascending, symmetrical, and affecting both sensation and motor function. This type of PN is frequently observed in POEMS syndrome, a rare entity, often misdiagnosed. ${ }^{20}$ Finally, Kosturakis et al ${ }^{21}$ recently demonstrated that patients with MM commonly present sensory and sensorimotor deficits at the onset as a result of disease-related decreases in peripheral innervation density.

In addition to the disease itself, comorbidities such as the presence of diabetes mellitus, alcohol abuse, vitamin deficiencies, or viral infections can increase PN; therefore, an accurate investigation and clinical history are mandatory at the diagnosis.

Some authors reported that the expression of genes involved in drug-induced apoptosis, mitochondrial dysfunction, and peripheral nervous system development, analyzed by gene expression profiling, seems to be significantly associated with the early onset of BiPN..$^{22,23}$ In addition, single-nucleotide polymorphisms located in genes involved

Table 2 Total neuropathy score

\begin{tabular}{|c|c|c|c|c|c|}
\hline \multirow[t]{2}{*}{ Parameter } & \multicolumn{5}{|l|}{ Score } \\
\hline & 0 & I & 2 & 3 & 4 \\
\hline Sensory symptoms & None & $\begin{array}{l}\text { Symptoms limited to } \\
\text { fingers or toes }\end{array}$ & $\begin{array}{l}\text { Symptoms extend to } \\
\text { ankle or wrist }\end{array}$ & $\begin{array}{l}\text { Symptoms extend to } \\
\text { knee or elbow }\end{array}$ & $\begin{array}{l}\text { Symptoms above } \\
\text { knees or elbows, or } \\
\text { functionally disabling }\end{array}$ \\
\hline Motor symptoms & None & Slight difficulty & Moderate difficulty & $\begin{array}{l}\text { Require help or } \\
\text { assistance }\end{array}$ & Paralysis \\
\hline $\begin{array}{l}\text { Number of } \\
\text { autonomic symptoms }\end{array}$ & None & One & Two & Three & Four or five \\
\hline Pin sensibility & Normal & $\begin{array}{l}\text { Reduced in fingers and/ } \\
\text { or toes }\end{array}$ & $\begin{array}{l}\text { Reduced up to wrist } \\
\text { and/or ankle }\end{array}$ & $\begin{array}{l}\text { Reduced up to elbow } \\
\text { and/or knee }\end{array}$ & $\begin{array}{l}\text { Reduced above elbow } \\
\text { and/or knee }\end{array}$ \\
\hline Vibration sensibility & Normal & $\begin{array}{l}\text { Reduced in fingers and/ } \\
\text { or toes }\end{array}$ & $\begin{array}{l}\text { Reduced up to wrist } \\
\text { and/or ankle }\end{array}$ & $\begin{array}{l}\text { Reduced up to elbow } \\
\text { and/or knee }\end{array}$ & $\begin{array}{l}\text { Reduced above elbow } \\
\text { and/or knee }\end{array}$ \\
\hline Strength & Normal & Mild weakness & Moderate weakness & Severe weakness & Paralysis \\
\hline Tendon reflex & Normal & Ankle reflex reduced & Ankle reflex absent & $\begin{array}{l}\text { Ankle reflex absent, } \\
\text { others reduced }\end{array}$ & All reflexes absent \\
\hline $\begin{array}{l}\text { Vibration sensibility } \\
\text { (QST vibration) }^{\mathrm{a}}\end{array}$ & $\begin{array}{l}\text { Normal to } 125 \% \text { of } \\
\text { ULN }\end{array}$ & $126 \%-150 \%$ of ULN & $15 \mid \%-200 \%$ of ULN & $201 \%-300 \%$ of ULN & $>300 \%$ of ULN \\
\hline Sural amplitude ${ }^{b}$ & $\begin{array}{l}\text { Normal or reduced } \\
\text { to }<5 \% \text { of } \mathrm{LLN}\end{array}$ & $76 \%-95 \%$ of LLN & $51 \%-75 \%$ of LLN & $26 \%-50 \%$ of LLN & $0-25 \%$ of LLN \\
\hline Peroneal amplitude ${ }^{b}$ & $\begin{array}{l}\text { Normal or reduced } \\
\text { to }<5 \% \text { of } \mathrm{LLN}\end{array}$ & $76 \%-95 \%$ of LLN & $51 \%-75 \%$ of LLN & $26 \%-50 \%$ of LLN & $0-25 \%$ of LLN \\
\hline
\end{tabular}

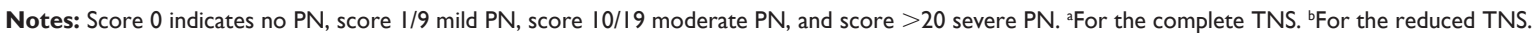

Abbreviations: PN, peripheral neuropathy; TNS, total neuropathy score; QST, quantitative sensory testing; ULN, upper limit of normal; LLN, lower limit of normal. 
in cell death, DNA repair, and the development and function of the nervous system may also be associated with BiPN and TiPN, although the identified genes were distinct for each one. ${ }^{24}$

\section{Treatment-related PN}

Treatment-related PN depends on the drug used, the dosage, and the cumulative dose administered; it is usually symmetric and distal and dramatically affects the quality of life of patients, leading frequently to dose reduction, delay, or even discontinuation of a successful treatment. Vinca alkaloids and platinum compounds in the past era and more recently thalidomide and bortezomib mainly caused PN.

\section{Vinca alkaloids}

Vinca alkaloids inhibit the mitotic spindle and microtubule assembly, leading to distal axonopathy because axonal transport is microtubule dependent. Vincristine is the most neurotoxic, leading to $\mathrm{PN}$ in $30 \%-40 \%$ of treated patients. The severity is related to total cumulative dose; PN usually appears over the dose of $4 \mathrm{mg} / \mathrm{m}^{2}$. Sensory signs appear first; distal motor weakness as well as neuropathic pain and autonomic dysfunction is not uncommon. Distal segments of the nerves are predominantly involved. ${ }^{25,26}$ Vincristine-induced PN may start with paresthesia in the fingers instead of toes but can also lead to ataxia, pain, and (distal) muscle weakness, resulting in foot drop. However, a significant proportion of patients will also develop autonomic symptoms, like urinary retention and erectile dysfunction. NCS may show a reduction in the amplitude of both sensory nerve and compound motor nerve action potentials. Signs and symptoms usually improve in months with dose reduction or discontinuation of the drug. ${ }^{27,28}$

\section{Platinum compounds}

PN occurs in $\sim 30 \%$ of patients treated with cisplatinum, and $20 \%$ of them have to stop treatment. The toxicity is related to the total cumulative dose $\left(500-600 \mathrm{mg} / \mathrm{m}^{2}\right)$ but not to the dose intensity of treatment and is prevalently directed to the dorsal root ganglion (DRG) by damage of mitochondrial DNA and crosslink of DNA, leading to its alteration and consequent apoptosis. Cisplatinum typically affects sensory neurons of large diameter. The patients almost invariably present with nonpainful paresthesias in hands and feet, with loss of sense of vibration, position, and movement and reduced myotatic reflexes. Symptoms may start or progress after the end of treatment, but a gradual improvement occurs in most patients. NCS demonstrate sensory axonal damage with reduced SNAPs, while conduction velocity and motor nerve conduction remain normal. ${ }^{29}$

\section{Thalidomide}

TiPN is mainly a sensory axonal polyneuropathy that can also occur at the end of treatment, which is cumulative, dose dependent, and often irreversible. As usual, the clinical manifestations include bilateral and symmetrical sensory disorders, more rarely motor disorders or dysautonomia. The patients initially report stinging sensations or numbness (distal paresthesia and hyperesthesia) affecting the toes or sometimes the fingers, which may extend proximally. Trembling is very common but rarely interferes with daily activities initially. With the increase in severity, the deep vibratory sensitivity and proprioception may also cause progressive ataxia, difficulty in walking, and trembling. In NCS, TiPN reveals most frequently a length-dependent axonal neuropathy, a sign of a dying-back degeneration of sensory and motor nerves. Large myelinated neurons are mainly affected, with preservation of small fibers and limited evidence for demyelination. Degeneration of DRG has also been reported. ${ }^{30-34}$ As a sign of sensorimotor axonal neuropathy, thalidomide usually produces a $50 \%$ decrease in SNAPs, concurrently with sensory changes. ${ }^{31,35-38}$ The mechanism is not clear, but probably linked to the angiogenesis inhibition and cytokine modulation..$^{29}$ Another hypothesis is the capillary damage and secondary anoxemia in nerve fibers. Additionally, thalidomide could reduce neuronal cell survival by downregulation of tumor necrosis factor alpha (TNF $\alpha$ ), inhibition of nuclear factor kappa beta, and subsequent acceleration of neuronal cell death, even if these data are debated. ${ }^{39}$ In fact, also lenalidomide shows a potent TNF $\alpha$ inhibition but does not cause important PN. Moreover, thalidomide has been proven to reduce neuropathic pain in refractory reflex sympathetic dystrophy, maybe through inhibition of cytokines, including TNF $\alpha$. This anti-inflammatory effect might also explain why a relevant increase in $\mathrm{PN}$ is not often observed when thalidomide or lenalidomide are combined with bortezomib. ${ }^{40,41}$

The incidence of TiPN reported in the literature is extremely variable, from $23 \%$ to $70 \%$, according to the study, the population analyzed (pretreated or naïve patients), and the length of exposure and dosage: ${ }^{42,43}$ however the majority of studies report PN in one-third or half of treated patients. ${ }^{44,45}$ The risk of neurotoxicity increases in a dose-dependent manner up to a cumulative dose of $20 \mathrm{~g}$. Actually, thalidomide is administered at a maximum dose of $200 \mathrm{mg}$ daily and for a limited treatment duration. ${ }^{46}$ Prolonged therapy $>1$ year is discouraged, not only for neurotoxicity but also for resistance; 
PN after 1 year of treatment reaches $75 \%$ of cases, with one-third of patients with grade 3 toxicity. ${ }^{47,48}$ In the recent years, thalidomide has become widely incorporated in front-line myeloma treatment for young patients in preparation for autologous transplantation in combination with bortezomib and high-dose dexamethasone. Also, elderly and/or frail patients are often treated with thalidomide with low-dose melphalan without apparent increase in PN compared to low-dose melphalan alone. ${ }^{49}$ Nevertheless, motor PN can complicate thalidomide treatment considering that concomitant high-dose dexamethasone can worsen muscle weakness and cause mild or moderate tremor. In addition, constipation occurs rapidly and frequently in patients with autonomic nerve fiber injury, with $\sim 75 \%$ of patients (all grades of toxicity).

\section{Bortezomib}

BiPN generally starts distally and may progress proximally; it is related to dose, schedule, and mode of administration and is usually reversible. It typically occurs within the first treatment cycles with bortezomib, reaching a plateau around cycle 5, without apparent increase in subsequent cycles. The incidence achieves a plateau at cumulative doses of $30-45 \mathrm{mg} / \mathrm{m}^{2}$. From the clinical point of view, BiPN is more a sensory rather than a motor PN (pain, paresthesia, burning sensation, dysesthesia, numbness, sensory loss) affecting the feet more than the hands. Reports of cold pain, positive sensory symptoms in a stocking-and-glove distribution, proprioception changes, impaired sharpness detection, and elevated thresholds for the detection of skin warming and heat pain are common; sometimes, patients may also present a suppression/reduction in their deep tendon reflexes..$^{38,41,50-52}$ Motor impairment is rare, even if the pain and stinging of the extremities result in a reduction in activity and in distal weakness in the lower limbs. In terms of dysautonomic neurotoxicity, orthostatic hypotension has been reported in $\sim 10 \%$ of the patients. From the electrophysiological point of view, NCS predominantly reveal low amplitude of SNAPs, in keeping with a length-dependent, sensory, axonal polyneuropathy, with predominant involvement of small fibers. ${ }^{53,54}$

BiPN is multifactorial and is prevalently related to the proteasome inhibition (Figure 1). The ubiquitin proteasome system (UPS) is the main proteolytic extralysosomal system in both cytoplasm and the nucleus, playing a key role in transcription, cell cycle regulation, proliferation, signaling, and apoptosis. Neoplastic cells, which have a high protein turnover, are extremely dependent on these regulatory pathways; hence, inhibition of the UPS reduces survival of tumor cells. Neurons are quiescent cells but suffer from proteasome inhibition because of their high metabolic activity; UPS impairment leads to protein aggregation due to failure to remove misfolded proteins. As support for this hypothesis, impairment of the proteasome has been related to some neurodegenerative diseases, such as Alzheimer, Parkinson,

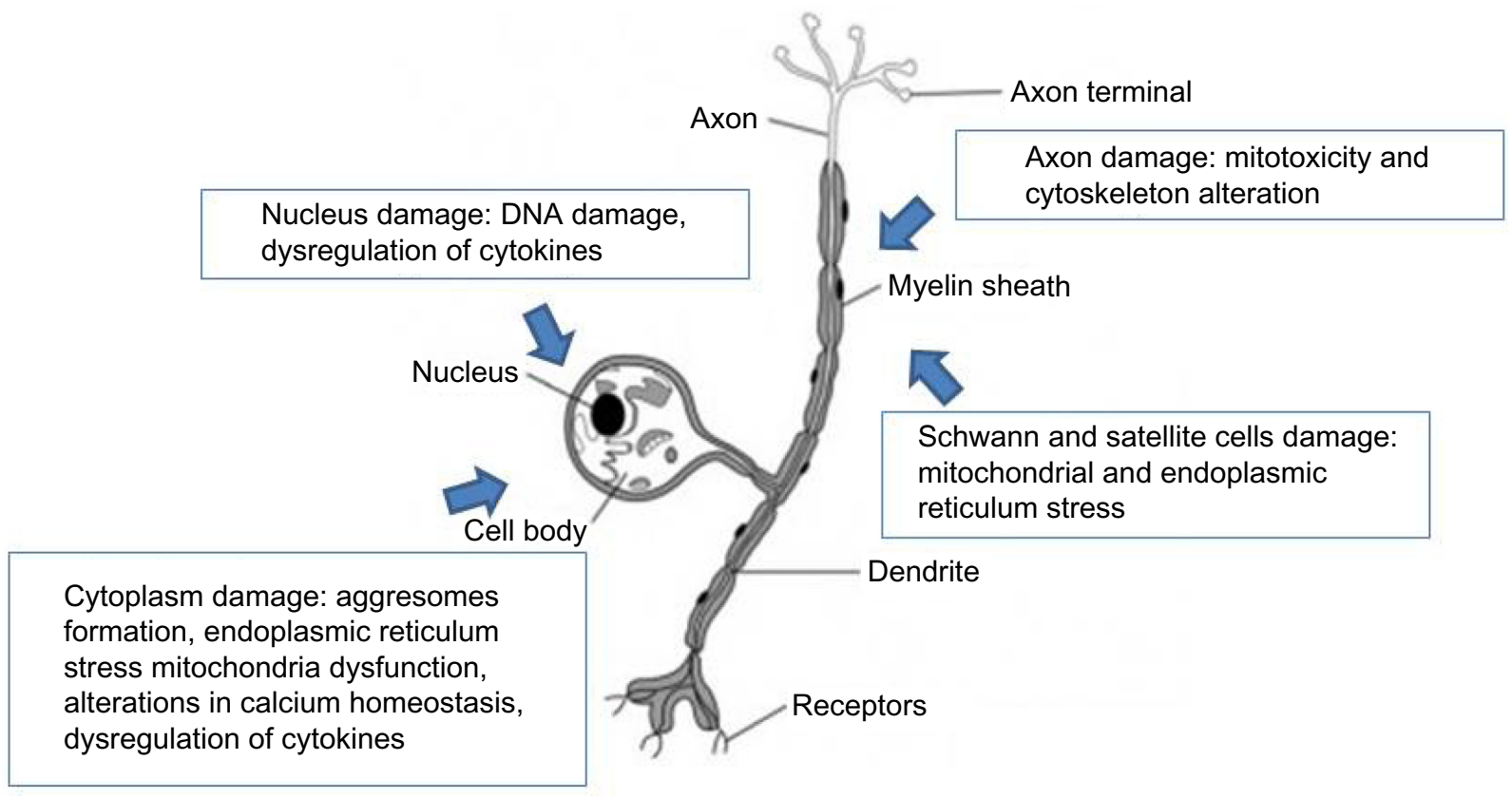

Figure I Principal mechanisms of neuronal damage induced by bortezomib: ubiquitinated protein accumulated in the cytoplasm with production of aggresomes, endoplasmic reticulum stress, mitochondria dysfunction, axonal transport damage due to mitotoxicity and cytoskeleton alteration, DNA damage, and dysregulation of cytokines. 
Huntington's chorea, and amyotrophic lateral sclerosis. ${ }^{55}$ The inhibition of UPS by bortezomib causes accumulation of ubiquitinated proteins in the cytoplasm with the creation of autophagic/lysosomal vesicles that induce endoplasmic reticulum stress, which leads to alterations in calcium homeostasis and mitochondria impairment. ${ }^{56,57}$ In addition, mitochondria dysfunctions are observed for mitotoxicity or damaged axonal transport due to cytoskeleton alterations that cause impairment of the mitochondria trafficking. ${ }^{58,59}$ DNA damage signaling alters nuclear structure and dysregulates protein synthesis. ${ }^{53,60-67}$ Finally, induction of a proinflammatory response and secretion of cytokines can also lead to neurotoxicity, and the inhibition of the activation of nuclear factor-kappa beta can block the nerve growth factor-mediated neuronal survival. ${ }^{68}$ The most damaged cells during bortezomib treatment are usually neuronal cell bodies within the DRG and their axons extending in the extremities to a lesser extent. Mitochondrial and endoplasmic reticulum damages in both Schwann and satellite cells have also been observed (Figure 1).

The overall incidence of BiPN varies from $31 \%$ to $45 \%$ for all grades. ${ }^{52}$ In the first Phase II studies for pretreated relapsed/refractory MM patients, SUMMIT (Study of Uncontrolled Multiple Myeloma Managed with Proteasome Inhibition Therapy) and CREST (Clinical Response and Efficacy Study of Bortezomib in the Treatment of Relapsing Multiple Myeloma), ${ }^{69,70}$ and in the Phase III study APEX (Assessment of Proteasome Inhibition for Extending Remissions), ${ }^{71,72}$ BiPN of all grades occurred in 35\%-37\% of patients receiving bortezomib $1.3 \mathrm{mg} / \mathrm{m}^{2}$ and in $21 \%$ of patients receiving bortezomib $1.0 \mathrm{mg} / \mathrm{m}^{2}$, BiPN of grade 3 was observed in 9\%-13\% of patients, and BiPN of grade 4 occurred in $<1 \%$ of patients. Approximately $12 \%$ of patients needed dose adjustment and $5 \%$ of patients withdrew therapy for neurotoxic effects; resolution to baseline or improvement occurred in $64 \%-71 \%$ of patients with a median of 47 days or 110 days, respectively. In the Intergroupe Francophone du Myélome (IFM) trial for newly diagnosed young patients treated with bortezomib in the induction regimen followed by autologous stem cell transplantation, BiPN occurred in $47 \%$ of patients, with $16 \%$ showing grade 3 or $4 .{ }^{73}$ For the same population of patients, the HOVON-65/GMMG-HD4 trial used bortezomib as induction and also maintenance treatment; BiPN was observed in $37 \%$ of patients during induction, with $24 \%$ of grades $3-4 .^{74}$ In elderly patients, bortezomib in combination with melphalan and prednisone leads to $44 \%$ of overall BiPN with $13 \%$ of grades $3-4 ;^{75} 74 \%$ of PN events had either resolved $(56 \%)$ or decreased $(18 \%)$ in a median of 2 months. Interestingly, when bortezomib was combined with thalidomide or lenalidomide, this did not further increase the rate of treatment-induced PN. In fact, PN of grades 3-4 occurred in 10\% of newly diagnosed MM patients treated with bortezomib, thalidomide, and dexamethasone $^{76}$ and in $14 \%$ of relapsed/refractory MM patients treated with bortezomib, lenalidomide, and dexamethasone. ${ }^{77}$ Considering untreated MM patients ineligible for transplantation, severe PN was observed in $11 \%$ of patients receiving velcade, melphalan, prednisone and thalidomide as induction followed by velcade plus thalidomide as maintenance treatment; on the other hand severe PN was reported in 5\% of patients treated with velcade, melphalan and prednisone. ${ }^{78}$ The median time to onset of BiPN is $\sim 2.3$ months. BiPN usually improves or completely resolves in most patients after a median of 3 months after discontinuation of treatment. However, there are reports in which the recovery from pain and other sensory neuropathic symptoms required up to 2 years after bortezomib discontinuation. ${ }^{79}$ Motor or autonomic PN rarely affects patients who receive bortezomib, but diarrhea or constipation and orthostasis can complicate therapy in $10 \%-15 \%$ of patients who receive bortezomib.

It is important to note that once BiPN has resolved, there is no increased risk for cumulative BiPN upon retreatment with bortezomib. ${ }^{80}$

New generation PIs have been developed in an effort to overcome resistance to bortezomib and side effects. The incidence of PN with carfilzomib is $\sim 13 \%$, including patients with baseline PN. ${ }^{66,81,82}$ Oral ixazomib in Phase II studies showed grades 3-4 PN in less than $6 \%$ of patients. ${ }^{83,84}$

\section{Lenalidomide}

Lenalidomide is a second-generation IMiD with more potent anti-inflammatory and antiangiogenic activities than thalidomide, first approved in combination with dexamethasone for relapsed/refractory MM patients who had received at least one prior therapy. Recently, the US Food and Drug Administration extended the approval also as the first-line treatment. This drug downregulates proinflammatory cytokines, upregulates anti-inflammatory cytokines, and reduces cell surface adhesion molecules. In addition, it presents antiangiogenic and antiproliferative activities. Moreover, lenalidomide binds cereblon, a protein encoded by the $C R B N$ gene, which forms an E3 ubiquitin ligase complex involved in proteolysis of specific proteins. Particularly, lenalidomide potentiates the proteolysis of Ikaros family zinc finger proteins 1 and 3 (IKZF1 and IKZF3), important transcription factors for B-cell differentiation, and downregulation of interferon-regulatory factor 4 and c-Myc, inducing 
cytotoxicity of myeloma cells. ${ }^{85,86}$ Lenalidomide does not seem to cause substantial neurotoxicity. PN of grades 1-2 has been observed in $18 \%-24 \%$ cases, considering also that the majority of these patients had a prior history of PN. ${ }^{87-89}$ Rare cases of central neurotoxicity with IMiDs have been reported. ${ }^{90}$ New IMiD pomalidomide causes very few incidences of $\mathrm{PN} ;<5 \%$. $^{91,92}$

\section{Drugs modification and intervention}

Prompt recognition of signs and symptoms and early intervention are extremely important. Particularly, TiPN symptoms can often aggravate and become irreversible. Since the occurrence of TiPN is not predictable and a preventive treatment still does not exist, it is important to minimize other potential risk factors for PN such as vitamin B12 deficiency or diabetes. Once treatment is initiated, it has been suggested that thalidomide has to be limited to $200 \mathrm{mg} / \mathrm{d}$ to minimize TiPN and should be dose reduced or discontinued in patients with grade 2 or 3 TiPN, respectively. After reduction, thalidomide can be restarted with a $50 \%$ dose reduction upon resolution to grade 1 if the risk-benefit ratio is favorable (Table 3). In some cases, also patients with grade 1 TiPN can benefit from a thalidomide dose reduction by $50 \%$. During maintenance treatment, the thalidomide dose could be reduced to $50 \mathrm{mg} / \mathrm{d}$ as soon as the patient has achieved a plateau response; prolonged use $>12$ months is not recommended. ${ }^{41,93}$ For elderly patients ( $>75$ years), a daily thalidomide dose of $100 \mathrm{mg}$ can be considered, with dose reduction to $50 \mathrm{mg} / \mathrm{d}$ in the case of $\mathrm{PN}$. ${ }^{94,95}$

In the case of BiPN, lower doses of bortezomib, weekly administration, or different schedules (4-week cycles instead of 3-week cycles) may be used. ${ }^{96}$ In fact, bortezomib should be progressively reduced from $1.3 \mathrm{mg} / \mathrm{m}^{2}$ to $1.0 \mathrm{mg} / \mathrm{m}^{2}$ up to $0.7 \mathrm{mg} / \mathrm{m}^{2}$ in the case of severe or persistent damage (Table 4). Moreover, once-weekly instead of twice-weekly application can be performed. Recently, a multiagent study has shown that, in addition to dose reduction, weekly dosing may prevent the progression of PN and reduce severity without affecting efficacy. ${ }^{97}$ The Gruppo Italiano Malattie

Table 3 Algorithm for the management of TiPN

\begin{tabular}{ll}
\hline PN grade & TiPN management \\
\hline I & Thalidomide dose reduction by $50 \%$ \\
2 & Thalidomide discontinuation until resolution \\
& or improvement to grade I \\
& Restart with a $50 \%$ dose reduction \\
$3-4$ & Definitive discontinuation \\
\hline
\end{tabular}

Abbreviations: TiPN, thalidomide-induced peripheral neuropathy; PN, peripheral neuropathy.
EMatologiche dell'Adulto (GIMEMA) showed a significantly lower incidence of PN with weekly versus biweekly bortezomib: an incidence of grades 3-4 PN of $8 \%$ in the once-weekly group and $28 \%$ in the twice-weekly group was observed; $5 \%$ of patients in the once-weekly group and $15 \%$ in the twice-weekly group discontinued therapy because of PN. The overlapping results in terms of overall survival and progression-free survival between the two arms were reported. ${ }^{98}$ Finally, subcutaneous (SC) rather than intravenous (IV) administration is actually recommended. In a recent trial, 222 relapsed MM patients were randomized to SC or IV administration of bortezomib. The overall response rates after four cycles were identical in both arms, and no significant difference was observed in the time to overall survival and progression-free survival. BiPN grades $1-4$ (38\% vs $53 \%$ ), grade $2(24 \%$ vs $41 \%)$, and grade 3 (6\% vs $16 \%$ ) were significantly lower with SC versus IV administration of bortezomib. ${ }^{99}$ Also other groups reported less neurotoxicity with SC administration. ${ }^{100-103}$

As supportive care, vitamin B, antioxidants such as vitamin E, alpha-lipoic acid, glutathione, and supplements with glutamine or acetyl-L-carnitine can be used. However, administration of pyridoxine (vitamin B6) can cause additional sensory neuropathy in patients with impaired renal function and in association with a protein-deficient diet; vitamin $\mathrm{C}$ may interfere with bortezomib metabolism and may also abrogate bortezomib-mediated inhibition of proteasome activity. Therefore, careful attention is recommended, especially during the days of bortezomib administration. The drugs to alleviate BiPN include gabapentin or pregabalin; tricyclic antidepressants such as amitriptyline, nortriptyline, and imipramine; serotonin and norepinephrine reuptake inhibitors; carbamazepine; and opioid-type analgesics. The local application of lidocaine or menthol-containing analgesic cream can temporarily alleviate bortezomib-induced pain.

Some authors propose first to use pregabalin (150$600 \mathrm{mg} / \mathrm{d})$ for at least 3 months or gabapentin $(300-2,400 \mathrm{mg} / \mathrm{d})$.

Table 4 Algorithm for the management of BiPN

\begin{tabular}{ll}
\hline PN grade & BiPN management \\
\hline I & $\begin{array}{l}\text { Twice-weekly administration: dose reduction to } \\
\text { level }- \text { I or change to weekly administration } \\
\text { Weekly administration: dose reduction to level -I } \\
\text { Temporary discontinuation of bortezomib or } \\
\text { further dose reduction to level }-2\end{array}$ \\
$\begin{array}{ll}\text { I with pain or } 2 & \text { Definitive discontinuation }\end{array}$ \\
$\begin{array}{l}\text { Note: Dose reduction of bortezomib: standard dose, I.3 } \mathrm{mg} / \mathrm{m}^{2} ; \text { reduction to } \\
\text { level -I, I mg/m²; and reduction to level }-2,0.7 \mathrm{mg} / \mathrm{m}^{2} .\end{array}$ \\
$\begin{array}{l}\text { Abbreviations: BiPN, bortezomib-induced peripheral neuropathy; PN, peripheral } \\
\text { neuropathy. }\end{array}$
\end{tabular}


In case of failure, duloxetine $(30-60 \mathrm{mg} / \mathrm{d})$ is considered as a valid second-line choice. Tramadol can reduce chronic pain. $^{38}$

However, the recommendations from the British Committee for Standards in Haematology in MM are

- oral tramadol for mild-moderate pain;

- oral oxycodone or alternatively morphine for chronic moderate-severe pain; and

- SC opioid therapy (oxycodone or morphine injection) for acute severe pain. ${ }^{104,105}$

Moreover, patients should be advised to:

- wear loose-fitting shoes, roomy socks, and padded slippers;

- soak feet in icy water and massage the feet for temporary pain relief;

- keep feet uncovered in bed because pressing on the toes can add to the problem; and

- walk to help circulation in the feet, even if too much walking or standing can make the problem worse.

Patients suffering from severe PN and having difficulty in the execution of daily activities can benefit from physical exercise and physiotherapy. Adequate fiber and fluid intake, stool softeners, and laxatives are recommended for the prevention of treatment-induced constipation (and also to avoid side effects of painkillers). Patients with autonomic dysfunctions should rise cautiously, avoid demanding physical tasks, and drive vehicles or operate machinery with caution; hydration, adjustment of antihypertensive medications, increased salt intake, and eventually low-dose mineralocorticoids can be helpful for orthostasis..$^{28,29,38,41,105}$ More recently, menthol, a topical transient receptor potential melastatin 8 receptor activator, seems to be efficient for BiPN. ${ }^{106}$

\section{Conclusion}

Although the introduction of new drugs in the standard of care in MM patients leads to a significant improvement in their outcome, neurotoxicity is an important side effect, particularly related to the use of bortezomib and thalidomide causing BiPN and TiPN, respectively. Patients, who sometimes present $\mathrm{PN}$ at baseline, related to the disease, are often forced to reduce or stop treatment because of the development of important neurotoxicity. Even if they are able to complete the planned treatment, they can suffer from signs and symptoms that significantly affect their quality of life. A close monitoring of predisposing factors at baseline and regular neurological assessment with scales for screening and grading of PN, such as the National Cancer Institute Common Toxicity Criteria or the TNS, are extremely important. At the appearance of signs and symptoms, modification of dosage and/or frequency of administration are recommended, together with concomitant treatments to relieve pain. Second-generation PIs and IMiDs, such as carfilzomib and pomalidomide, revealed good efficacy and lower neurotoxicity, representing a promising option for the treatment of MM patients.

\section{Author contributions}

SG, LC, and MTP acquired, analyzed, and interpreted the data and drafted the article. SG and MTP revised it and approved the final version. The questions related to the accuracy or integrity of any part of the work were appropriately investigated and resolved by SG, LC, and MTP. All authors contributed toward data analysis, drafting and critically revising the paper and agree to be accountable for all aspects of the work.

\section{Disclosure}

The authors report no conflicts of interest in this work.

\section{References}

1. Kelly JJ. The evaluation of peripheral neuropathy. Part I: clinical and laboratory evidence. Rev Neurol Dis. 2004;1(3):133-140.

2. Drappatz J, Batchelor T. Neurologic complications of plasma cell disorders. Clin Lymphoma. 2004;5(3):163-171.

3. Dispenzieri A, Kyle RA. Neurological aspects of multiple myeloma and related disorders. Best Pract Res Clin Haematol. 2005;18(4):673-688.

4. Cata JP, Weng HR, Burton AW, Villareal H, Giralt S, Dougherty PM. Quantitative sensory findings in patients with bortezomib-induced pain. J Pain. 2007;8(4):296-306.

5. Windebank AJ, Grisold W. Chemotherapy-induced neuropathy. J Peripher Nerv Syst. 2008;13(1):27-46.

6. Silberman J, Lonial S. Review of peripheral neuropathy in plasma cell disorders. Hematol Oncol. 2008;26(2):55-65.

7. National Cancer Institute. Common Toxicity Criteria version 4.0. Bethesda, MD: National Cancer Institute; 2010.

8. Cella DF, Tulsky DS, Gray G, et al. The functional assessment of cancer therapy scale: development and validation of the general measure. J Clin Oncol. 1993;11(3):570-579.

9. Calhoun EA, Welshman EE, Chang $\mathrm{CH}$, et al. Psychometric evaluation of the functional assessment of cancer therapy/gynecologic oncology group-neurotoxicity (Fact/GOG-Ntx) questionnaire for patients receiving systemic chemotherapy. Int J Gynecol Cancer. 2003;13(6):741-748.

10. Cavaletti G, Frigeni B, Lanzani F, et al; Italian NETox Group. The Total Neuropathy Score as an assessment tool for grading the course of chemotherapy-induced peripheral neurotoxicity: comparison with the National Cancer Institute-Common Toxicity Scale. J Peripher Nerv Syst. 2007;12(3):210-215.

11. Mendoza TR, Wang XS, Williams LA, et al. Measuring therapyinduced peripheral neuropathy: preliminary development and validation of the treatment-induced neuropathy assessment scale. J Pain. 2015;16(10):1032-1043.

12. Rolke R, Magerl W, Campbell KA, et al. Quantitative sensory testing: a comprehensive protocol for clinical trials. Eur J Pain. 2006;10(1):77-88.

13. Postma TJ, Aaronson NK, Heimans JJ, et al; EORTC Quality of Life Group. The development of an EORTC quality of life questionnaire to assess chemotherapy-induced peripheral neuropathy: the QLQ-CIPN20. Eur J Cancer. 2005;41(8):1135-1139. 
14. Beijers AJ, Vreugdenhil G, Oerlemans S, et al. Chemotherapy-induced neuropathy in multiple myeloma: influence on quality of life and development of a questionnaire to compose common toxicity criteria grading for use in daily clinical practice. Support Care Cancer. Epub 2015 Dec 3.

15. Notermans NC. Monoclonal gammopathy and neuropathy. Curr Opin Neurol. 1996;9(5):334-337.

16. Steck AJ, Czaplinski A, Renaud S. Inflammatory demyelinating neuropathies and neuropathies associated with monoclonal gammopathies: treatment update. Neurotherapeutics. 2008;5(4):528-534.

17. Sonneveld P, Jongen JL. Dealing with neuropathy in plasmacell dyscrasias. Hematology Am Soc Hematol Educ Program. 2010;2010:423-430

18. Rajabally AY. Neuropathy and paraproteins: review of a complex association. Eur J Neurol. 2011;18(11):1291-1298.

19. Sobol U, Stiff P. Neurologic aspects of plasma cell disorders. Handb Clin Neurol. 2014;120:1083-1099.

20. Dispenzieri A. POEMS syndrome: update on diagnosis, risk-stratification, and management. Am J Hematol. 2015;90(10):951-962.

21. Kosturakis AK, He Z, Li Y, et al. Subclinical peripheral neuropathy in patients with multiple myeloma before chemotherapy is correlated with decreased fingertip innervation density. J Clin Oncol. 2014;32(28):3156-3162.

22. Favis R, Sun $Y$, van de Velde $H$, et al. Genetic variation associated with bortezomib-induced peripheral neuropathy. Pharmacogenet Genomics. 2011;21(3):121-129.

23. Tacchetti P, Terragna C, Galli M, et al. Bortezomib- and thalidomideinduced peripheral neuropathy in multiple myeloma: clinical and molecular analyses of a phase 3 study. Am J Hematol. 2014;89(12): 1085-1091.

24. Johnson DC, Corthals SL, Walker BA, et al. Genetic factors underlying the risk of thalidomide-related neuropathy in patients with multiple myeloma. J Clin Oncol. 2011;29(7):797-804.

25. Tanner KD, Levine JD, Topp KS. Microtubule disorientation and axonal swelling in unmyelinated sensory axons during vincristineinduced painful neuropathy in rat. J Comp Neurol. 1998;395(4): 481-492.

26. Topp KS, Tanner KD, Levine JD. Damage to the cytoskeleton of large diameter sensory neurons and myelinated axons in vincristineinduced painful peripheral neuropathy in the rat. J Comp Neurol. 2000;424(4):563-576.

27. Verstappen CC, Koeppen S, Heimans JJ, et al. Dose-related vincristineinduced peripheral neuropathy with unexpected offtherapy worsening Neurology. 2005;64(6):1076-1077.

28. Argyriou AA, Bruna J, Marmiroli P, Cavaletti G. Chemotherapy-induced peripheral neurotoxicity (CIPN): an update. Crit Rev Oncol Hematol. 2012;82(1):51-77.

29. Jongen JLM, Broijl A, Sonneveld P. Chemotherapy-induced peripheral neuropathies in hematological malignancies. $J$ Neurooncol. 2015;121(2):229-237.

30. Aronson IK, Yu R, West DP, Van den Broek H, Antel J. Thalidomideinduced peripheral neuropathy. Effect of serum factor on nerve cultures. Arch Dermatol. 1984;120(11):1466-1470.

31. Cavaletti G, Beronio A, Reni L, et al. Thalidomide sensory neurotoxicity: a clinical and neurophysiologic study. Neurology. 2004;62(12):2291-2293.

32. Isoardo G, Bergui M, Durelli L, et al. Thalidomide neuropathy: clinical, electrophysiological and neuroradiological features. Acta Neurol Scand. 2004;109(3):188-193.

33. Laaksonen S, Remes K, Koskela K, Voipio-Pulkki LM, Falck B. Thalidomide therapy and polyneuropathy in myeloma patients. Electromyogr Clin Neurophysiol. 2005;45(2):75-86.

34. Zara G, Ermani M, Rondinone R, Arienti S, Doria A. Thalidomide and sensory neurotoxicity: a neurophysiological study. J Neurol Neurosurg Psychiatry. 2008;79(11):1258-1261.

35. Fullerton PM, O'Sullivan DJ. Thalidomide neuropathy: a clinical electrophysiological, and histological follow-up study. J Neurol Neurosurg Psychiatry. 1968;31(6):543-551.
36. Mileshkin L, Stark R, Day B, Seymour JF, Zeldis JB, Prince HM. Development of neuropathy in patients with myeloma treated with thalidomide: patterns of occurrence and the role of electrophysiologic monitoring. J Clin Oncol. 2006;24(27):4507-4514.

37. Plasmati R, Pastorelli F, Cavo M, et al. Neuropathy in multiple myeloma treated with thalidomide: a prospective study. Neurology. 2007;69(6):573-581.

38. Mohty B, El-Cheikh J, Yakoub-Agha I, Moreau P, Harousseau JL, Mohty M. Peripheral neuropathy and new treatments for multiple myeloma: background and practical recommendations. Haematologica. 2010;95(2):311-319.

39. Fernyhough P, Smith DR, Schapansky J, et al. Activation of nuclear factor-(kappa)B via endogenous tumor necrosis factor (alpha) regulates survival of axotomized adult sensory neurons. J Neurosci. 2005;25(7):1682-1690.

40. Mazumder A, Jagannath S. Thalidomide and lenalidomide in multiple myeloma. Best Pract Res Clin Haematol. 2006;19(4):769-780.

41. Delforge M, Bladé J, Dimopoulos MA, et al. Treatment-related peripheral neuropathy in multiple myeloma: the challenge continues. Lancet Oncol. 2010;11(11):1086-1095.

42. Dimopoulos MA, Zervas K, Kouvatseas G, et al. Thalidomide and dexamethasone combination for refractory multiple myeloma. Ann Oncol. 2001;12(7):991-995.

43. Prince HM, Mileshkin L, Roberts A, et al. A multicenter phase II trial of thalidomide and celecoxib for patients with relapsed and refractory multiple myeloma. Clin Cancer Res. 2005;11(15):5504-5514.

44. Glasmacher A, Hahn C, Hoffmann F, et al. A systematic review of phase-II trials of thalidomide monotherapy in patients with relapsed or refractory multiple myeloma. Br J Haematol. 2006;132(5):584-593.

45. von Lilienfeld-Toal M, Hahn-Ast C, Furkert K, et al. A systematic review of phase II trials of thalidomide/dexamethasone combination therapy in patients with relapsed or refractory multiple myeloma. Eur J Haematol. 2008;81(4):247-252.

46. Wechalekar AD, Chen CI, Sutton D, Reece D, Voralia M, Stewart AK. Intermediate dose thalidomide ( $200 \mathrm{mg}$ daily) has comparable efficacy and less toxicity than higher doses in relapsed multiple myeloma. Leuk Lymphoma. 2003;44(7):1147-1149.

47. Tosi P, Zamagni E, Cellini C, et al. Neurological toxicity of long-term $(>1 \mathrm{yr})$ thalidomide therapy in patients with multiple myeloma. Eur $J$ Haematol. 2005;74(3):212-216.

48. Feyler S, Rawstron A, Jackson G, Snowden JA, Cocks K, Johnson RJ. Thalidomide maintenance following high-dose therapy in multiple myeloma: a UK myeloma forum phase 2 study. $\mathrm{Br} J$ Haematol. 2007;139(3):429-433

49. Hulin C, Facon T, Rodon P, et al. Efficacy of melphalan and prednisone plus thalidomide in patients older than 75 years with newly diagnosed multiple myeloma: IFM 01/01 trial. J Clin Oncol. 2009;27(22):3664-3670.

50. Richardson PG, Briemberg H, Jagannath S, et al. Frequency, characteristics, and reversibility of peripheral neuropathy during treatment of advanced multiple myeloma with bortezomib. J Clin Oncol. 2006;24(19):3113-3120.

51. Chaudhry V, Cornblath DR, Polydefkis M, Ferguson A, Borrello I. Characteristics of bortezomib- and thalidomide-induced peripheral neuropathy. J Peripher Nerv Syst. 2008;13(4):275-282.

52. Argyriou AA, Cavaletti G, Bruna J, Kyritsis AP, Kalofonos HP. Bortezomib-induced peripheral neurotoxicity: an update. Arch Toxicol. 2014;88(9):1669-1679.

53. Bruna J, Udina E, Alé A, et al. Neurophysiological, histological and immunohistochemical characterization of bortezomib-induced neuropathy in mice. Exp Neurol. 2010;223(2):599-608.

54. Velasco R, Petit J, Clapes V, Verdu E, Navarro X, Bruna J. Neurological monitoring reduces the incidence of bortezomib-induced peripheral neuropathy in multiple myeloma patients. J Peripher Nerv Syst. 2010;15(1):17-25.

55. Taylor JP, Hardy J, Fischbeck KH. Toxic proteins in neurodegenerative disease. Science. 2002;296(5575):1991-1995. 
56. Landowski TH, Megli CJ, Nullmeyer KD, Lynch RM, Dorr RT. Mitochondrial-mediated disregulation of $\mathrm{Ca}^{2+}$ is a critical determinant of Velcade (PS-341/bortezomib) cytotoxicity in myeloma cell lines. Cancer Res. 2005;65(9):3828-3836.

57. Siau C, Bennett GJ. Dysregulation of cellular calcium homeostasis in chemotherapy-evoked painful peripheral neuropathy. Anesth Analg. 2006;102(5):1485-1490.

58. Poruchynsky MS, Sackett DL, Robey RW, WardY, Annunziata C, Fojo T. Proteasome inhibitors increase tubulin polymerization and stabilization in tissue culture cells: a possible mechanism contributing to peripheral neuropathy and cellular toxicity proteasome inhibition. Cell Cycle. 2008;7(7):940-949.

59. Nasu S, Misawa S, Nakaseko C, et al. Bortezomib-induced neuropathy: axonal membrane depolarization precedes development of neuropathy. Clin Neurophysiol. 2014;125(2):381-387.

60. Cavaletti G, Gilardini A, Canta A, et al. Bortezomib-induced peripheral neurotoxicity: a neurophysiological and pathological study in the rat. Exp Neurol. 2007;204(1):317-325.

61. Cavaletti G, Jakubowiak AJ. Peripheral neuropathy during bortezomib treatment of multiple myeloma: a review of recent studies. Leuk Lymphoma. 2010;51(7):1178-1187.

62. Meregalli C, Canta A, Carozzi VA, et al. Bortezomib-induced painful neuropathy in rats: a behavioural, neurophysiological and pathological studies in rats. Eur J Pain. 2010;14(4):343-350.

63. Carozzi VA, Canta A, Oggioni N, et al. Neurophysiological and neuropathological characterization of new murine models of chemotherapy induced chronic peripheral neuropathies. Exp Neurol. 2010;226(2):301-309.

64. Zheng H, Xiao WH, Bennett GJ. Mitotoxicity and bortezomibinduced chronic painful peripheral neuropathy. Exp Neurol. 2012;238(2):225-234.

65. Carozzi VA, Renn CL, Bardini M, et al. Bortezomib induced painful peripheral neuropathy: an electrophysiological, behavioral, morphological and mechanistic study in the mouse. PLoS One. 2013;8(9):e72995.

66. Ale' A, Bruna J, Navarro X, Udina E. Neurotoxicity induced by antineoplastic proteasome inhibitors. Neurotoxicology. 2014;43: $28-35$.

67. Alé A, Bruna J, Herrando M, Navarro X, Udina E. Toxic effects of bortezomib on primary sensory neurons and Schwann cells of adult mice. Neurotox Res. 2015;27(4):430-440.

68. Ravaglia S, Corso A, Piccolo G, et al. Immune-mediated neuropathies in myeloma patients treated with bortezomib. Clin Neurophysiol. 2008;119(11):2507-2512.

69. Richardson PG, Barlogie B, Berenson J, et al. A phase 2 study of bortezomib in relapsed, refractory myeloma. $N$ Engl $J$ Med. 2003;348(26):2609-2617.

70. Jagannath S, Barlogie B, Berenson J, et al. A phase 2 study of two doses of bortezomib in relapsed or refractory myeloma. Br J Haematol. 2004;127(2): 165-172.

71. Richardson PG, Sonneveld P, Schuster MW, et al. Bortezomib or highdose dexamethasone for relapsed multiple myeloma. $N$ Engl $J$ Med. 2005;352(24):2487-2498.

72. Richardson PG, Sonneveld P, Schuster MW, et al. Reversibility of symptomatic peripheral neuropathy with bortezomib in the phase III APEX trial in relapsed multiple myeloma: impact of a dose-modification guideline. Br J Haematol. 2009;144(6):895-903.

73. Harousseau JL, Attal M, Leleu X, et al. Bortezomib plus dexamethasone as induction treatment prior to autologous stem cell transplantation in patients with newly diagnosed multiple myeloma: results of an IFM phase II study. Haematologica. 2006;91(11): $1498-1505$.

74. Sonneveld P, Schmidt-Wolf I, van der Holt B, et al. Bortezomib induction and maintenance treatment in patients with newly diagnosed multiple myeloma: results of the randomized phase III HOVON-65/GMMG-HD4 trial. J Clin Oncol. 2012;30(24):2946-2955.
75. Mateos MV, Richardson PG, Schlag R, et al. Bortezomib plus melphalan and prednisone compared with melphalan melphalan and prednisone in previously untreated multiple myeloma: updated follow-up and impact of subsequent therapy in the phase III VISTA trial. J Clin Oncol. 2010;28(13):2259-2266.

76. Cavo M, Tacchetti P, Patriarca F, et al; GIMEMA Italian Myeloma Network. Bortezomib with thalidomide plus dexamethasone compared with thalidomide plus dexamethasone as induction therapy before, and consolidation therapy after, double autologous stem cell transplantation in newly diagnosed multiple myeloma: a randomised phase 3 study. Lancet. 2010;376(9758):2075-2085.

77. Dimopoulos MA, Kastritis E, Christoulas D, et al. Treatment of patients with relapsed/refractory multiple myeloma with lenalidomide and dexamethasone with or without bortezomib: prospective evaluation of the impact of cytogenetic abnormalities and of previous therapies. Leukemia. 2010;24(10):1769-1778.

78. Palumbo A, Bringhen S, Larocca A, et al. Bortezomib-melphalanprednisone-thalidomide followed by maintenance with bortezomibthalidomide compared with bortezomib-melphalan-prednisone for initial treatment of multiple myeloma: updated follow-up and improved survival. J Clin Oncol. 2014;32(7):634-640.

79. Chen CI, Kouroukis CT, White D, et al; National Cancer Institute of Canada Clinical Trials Group. Bortezomib is active in patients with untreated or relapsed Waldenstrom's macroglobulinemia: a phase II study of the National Cancer Institute of Canada Clinical Trials Group. J Clin Oncol. 2007;25(12):1570-1575.

80. Petrucci MT, Giraldo P, Corradini P, et al. A prospective, international phase 2 study of bortezomib retreatment in patients with relapsed multiple myeloma. Br J Haematol. 2013;160(5):649-659.

81. Siegel D, Martin T, Nooka A, et al. Integrated safety profile of singleagent carfilzomib: experience from 526 patients enrolled in 4 phase II clinical studies. Haematologica. 2013;98(11):1753-1761.

82. Kumar SK, Berdeja JG, Niesvizky R, et al. Safety and tolerability of ixazomib, an oral proteasome inhibitor, in combination with lenalidomide and dexamethasone in patients with previously untreated multiple myeloma: an open-label phase 1/2 study. Lancet Oncol. 2014;15(13):1503-1512.

83. Vij R, Wang L, Orlowski RZ, et al. Carfilzomib (CFZ), a novel proteasome inhibitor for relapsed or refractory multiple myeloma, is associated with minimal peripheral neuropathic effects. Blood. 2009;114:abstr430.

84. Offidani M, Corvatta L, Caraffa P, Gentili S, Maracci L, Leoni P. An evidence-based review of ixazomib citrate and its potential in the treatment of newly diagnosed multiple myeloma. Onco Targets Ther. 2014;7:1793-1800.

85. Zhu YX, Braggio E, Shi CX, et al. Cereblon expression is required for the antimyeloma activity of lenalidomide and pomalidomide. Blood. 2011;118(18):4771-4779.

86. Krönke J, Udeshi ND, Narla A, et al. Lenalidomide causes selective degradation of IKZF1 and IKZF3 in multiple myeloma cells. Science. 2014;343(6168):301-305

87. Dimopoulos M, Spencer A, Attal M, et al; Multiple Myeloma (010) Study Investigators. Lenalidomide plusdexamethasone for relapsed or refractory multiple myeloma. $N$ Engl J Med. 2007;357(21):2123-2132.

88. Weber DM, Chen C, Niesvizky R, et al. Lenalidomide plus dexamethasone for relapsed multiple myeloma in North America. $N$ Engl J Med. 2007;357(21):2133-2142.

89. Chen C, Reece DE, Siegel D, et al. Expanded safety experience with lenalidomide plus dexamethasone in relapsed or refractory multiplemyeloma. Br J Haematol. 2009;146(2):164-170.

90. Patel UH, Mir MA, Sivik JK, Raheja D, Pandey MK, Talamo G. Central neurotoxicity of immunomodulatory drugs in multiple myeloma. Hematol Rep. 2015;7(1):5704.

91. Lacy MQ, Hayman SR, Gertz MA, et al. Pomalidomide (CC4047) plus low-dose dexamethasone (pom/dex) is highly effective therapy in relapsed multiple myeloma. J Clin Oncol. 2009;27(30):5008-5014. 
92. Schey S, Ramasamy K. Pomalidomide therapy for myeloma. Expert Opin Investig Drugs. 2011;20(5):691-700.

93. Richardson PG, Delforge M, Beksac M, et al. Management of treatmentemergent peripheral neuropathy in multiple myeloma. Leukemia. 2012;26(4):595-608.

94. Palumbo A, Davies F, Kropff M, et al. Consensus guidelines for the optimal management of adverse events in newly diagnosed, transplantineligible patients receiving melphalan and prednisone in combination with thalidomide (MPT) for the treatment of multiple myeloma. Ann Hematol. 2010;89(8):803-811.

95. Koeppen S. Treatment of multiple myeloma: thalidomide-, bortezomib-, and lenalidomide-induced peripheral neuropathy. Oncol Res Treat. 2014;37(9):506-513.

96. Terpos E, Kleber M, Engelhardt M, et al. European Myeloma Network Guidelines for the management of multiple myeloma-related complications. Haematologica. 2015;100(10):1254-1266.

97. Mateos MV, Oriol A, Martínez-López J, et al; European Myeloma Network. Bortezomib, melphalan, and prednisone versus bortezomib, thalidomide, and prednisone as induction therapy followed by maintenance treatment with bortezomib and thalidomide versus bortezomib and prednisone in elderly patients with untreated multiple myeloma: a randomised trial. Lancet Oncol. 2010;11(10):934-941.

98. Bringhen S, Larocca A, Rossi D, et al. Efficacy and safety of once weekly bortezomib in multiple myeloma patients. Blood. 2010;116(23):4745-4753.

99. Moreau P, Pylypenko H, Grosicki S, et al. Subcutaneous versus intravenous administration of bortezomib in patients with relapsed multiple myeloma: a randomised, phase 3, non-inferiority study. Lancet Oncol. 2011;12(5):431-440.
100. Moreau P, Coiteux V, Hulin C, et al. Prospective comparison of subcutaneous versus intravenous administration of bortezomib in patients with multiple myeloma. Haematologica. 2008;93(12): 1908-1911.

101. Mateos MV, San Miguel JF. Safety and efficacy of subcutaneous formulation of bortezomib versus the conventional intravenous formulation in multiple myeloma. Ther Adv Hematol. 2012;3(2):117-124.

102. Koh Y, Lee SY, Kim I, et al. Bortezomib-associated peripheral neuropathy requiring medical treatment is decreased by administering the medication by subcutaneous injection in Korean multiple myeloma patients. Cancer Chemother Pharmacol. 2014;74(3):653-657.

103. Lok A, Mocquard J, Bourcier J, et al. Subcutaneous bortezomib incorporated into the bortezomib-thalidomide-dexamethasone regimen as part of front-line therapy in the context of autologous stem cell transplantation for multiple myeloma. Haematologica. 2014;99(3):e33-e34.

104. Bird JM, Owen RG, D'Sa S, et al; Haemato-oncology Task Force of British Committee for Standards in Haematology (BCSH) and UK Myeloma Forum. Guidelines for the diagnosis and management of multiple myeloma 2011. Br J Haematol. 2011;154(1):32-75.

105. Morawska M, Grzasko N, Kostyra M, Wojciechowicz J, Hus M. Therapy-related peripheral neuropathy in multiple myeloma patients. Hematol Oncol. 2015;33(4):113-119.

106. Fallon MT, Storey DJ, Krishan A, et al. Cancer treatment-related neuropathic pain: proof of concept study with menthol - a TRPM8 agonist. Support Care Cancer. 2015;23(9):2769-2777.
Blood and Lymphatic Cancer: Targets and Therapy

\section{Publish your work in this journal}

Blood and Lymphatic Cancer: Targets and Therapy is an international, peer-reviewed, open access journal focusing on blood and lymphatic cancer research, identification of therapeutic targets and the optimal use of preventative and integrated treatment interventions to achieve improved outcomes, enhanced survival and quality of life for the

\section{Dovepress}

cancer patient. The manuscript management system is completely online and includes a very quick and fair peer-review system. Visit http://www.dovepress.com/testimonials.php to read real quotes from published authors. 